Article

\title{
Association between Anatomical Variations and Maxillary Canine Impaction: A Retrospective Study in Orthodontics
}

\author{
Marco Pasini ${ }^{1, *}$, Maria Rita Giuca ${ }^{1}$, Sara Ligori ${ }^{1}$, Stefano Mummolo ${ }^{2} \mathbb{D}$, Fabiana Fiasca ${ }^{2} \mathbb{D}$, \\ Giuseppe Marzo $^{2}$ (D) and Vincenzo Quinzi ${ }^{2}$ (D) \\ 1 Department of Surgical, Medical, Molecular and Critical Area Pathology, University of Pisa, 56126 Pisa, Italy; \\ mariarita.giuca@med.unipi.it (M.R.G.); ligorisara@gmail.com (S.L.) \\ 2 Department of Life, Health and Environmental Sciences, University of L'Aquila, 67100 L'Aquila, Italy; \\ stefano.mummolo@univaq.it (S.M.); fabiana.fiasca@alice.it (F.F.); giuseppe.marzo@univaq.it (G.M.); \\ vincenzo.quinzi@univaq.it (V.Q.) \\ * Correspondence: dr.marcopasini@yahoo.it
}

Received: 8 July 2020; Accepted: 12 August 2020; Published: 14 August 2020

\begin{abstract}
This study aims to evaluate whether or not there is a higher prevalence of skeletal abnormalities in subjects with maxillary canine impaction (MCI). This retrospective study was performed on 67 subjects with maxillary canine impaction (test group) and on 67 patients without dental displacement (control group). Sella turcica bridging (SB), ponticulus posticus (PP), atlas posterior arch deficiency (APAD) and the morphology of sella turcica and pterygopalatine fissure were evaluated on lateral cephalometric radiographs. Statistical analysis was performed using chi-square, Mann-Whitney test and multivariate logistic models; the level of significance was $p<0.05$. Results showed that in the test and control groups $87 \%$ and $62.7 \%$ of patients had SB, respectively. PP was observed in $60 \%$ of patients in the test group and in $16.4 \%$ of patients in the control group. APAD was observed in $9 \%$ of test group and in $4.5 \%$ of the control group. Skeletal anomalies were significantly increased $(p<0.05)$ in subjects with MCI. A significant difference between the groups was observed in regards to the shape of the pterygopalatine fissure, found to be less wide and longer in the test group. SB, PP and APAD were higher in subjects with MCI; furthermore, an elongated pterygopalatine fissure was significantly associated with MCI.
\end{abstract}

Keywords: orthodontics; canine impaction; skeletal anomalies; anatomical variations

\section{Introduction}

Maxillary canine impaction (MCI) is an anomaly that indicates the absence of the dental arch of the dental elements that remain included beyond the physiological age of eruption.

The etiologic factors may be genetic, systemic or localized. Cephalometric radiographs are indispensable for an orthodontic diagnosis but they also include other important information about craniofacial abnormalities. Different skeletal alterations have been observed, including: ponticulus posticus (PP), atlas posterior arch deficiency (APAD) and sella-turcica bridging (SB) [1]. PP is an abnormal bony bridge that arises from the posterior portion of the superior articular process and the posterolateral portion of the superior margin of the posterior arch of the atlas [2]. It was observed that anomalies of the skeletal atlas posterior arch can be detected in fewer than $5 \%$ of patients without any pathology; furthermore, it was stated that it can be linked with different symptoms [3]. SB has a prevalence of $1.1-22 \%$ and is defined as the fusion of the posterior and anterior clinoid processes; an increased ossification of the dura mater between the two clinoid processes is often linked to this anatomical variation. Furthermore, it was noticed that an abnormal embryological development of the 
sphenoid is often associated with this skeletal alteration [4-6]. SB might be associated with different systemic diseases [7] and tooth agenesis [8]. Some of these skeletal variations and developmental pathologies could be detected in children and adolescents and often precede other skeletal and dental alterations (i.e., dental inclusion) [9]. This is the reason why these characteristics have attracted the attention of orthodontists in order to verify their possible association with some dental problems. Indeed, a higher incidence of SB has been associated with MCI and this association may be caused by activation of neural crest cells or homeobox genes in growing children [10]. In fact, it was found that neural crest cells are involved in dental formation and can determine the alteration of tooth eruption [11].

$\mathrm{SB}, \mathrm{PP}$ and APAD have been previously reported in literature for MCI while other skeletal parameters, including sella turcica length, were not associated with $\mathrm{MCI}$, even if some results are partially contradictory in particular for APAD-Ghadimi et al. observed that PP and SB were significantly increased in the subjects with MCI while APAD was not associated with this dental anomaly [5]. However, in a previous study, APAD was significantly associated with palatally displaced canines [1]. Furthermore, Scribante et al. found a posited correlation between dental anomalies including MCI and SB, while the Sella Turcica dimension was not different in patients with MCI [6].

The purpose of the present retrospective study was to verify a correlation between skeletal anomalies and $\mathrm{MCI}$ in adolescents and the novel aspect of the study is that a new parameter was introduced: pterygopalatine fissure morphology. The null hypothesis is that there is no association between skeletal variations and MCI.

\section{Materials and Methods}

\subsection{Study Design and Participants}

This retrospective study was conducted on pre-treatment lateral cephalometric and panoramic radiographs of 134 subjects who consecutively visited the Department of Orthodontics; the entire patient sample in the period between 2015 and 2019 was investigated.

Lateral cephalometric and panoramic radiographs were performed for each patient before any orthodontic treatment.

The sample size calculation was based on the results of a study [5] that found prevalence rates for $\mathrm{PP}$ of $42.9 \%$ and $18.7 \%$ in subjects with $\mathrm{MCI}$ and in the control group, respectively. The sample size required to achieve $85 \%$ power at a $5 \%$ level of statistical significance was determined to be 64 patients in each group.

The test group included 67 patients with a confirmed diagnosis of unilateral MCI while the control group included 67 patients matched for age and sex and skeletal class prevalence without any dental anomaly. Moreover, the diagnosis of MCI was confirmed visually during dental surgery and it was recorded in the clinical file of each subject.

The inclusion criteria were: Caucasian subjects, diagnosis of unilateral MCI during the orthodontic treatment and the fact that the shapes of the skeletal variants needed to be clearly detectable, as well as at least the first four cervical vertebrae. $\mathrm{MCI}$ was diagnosed using the same $\mathrm{X}$-ray imaging machines. Lateral cephalometric radiographs were taken with teeth in centric occlusion, lips relaxed and head normally positioned.

The exclusion criteria comprised: incomplete patient files, poor quality images, nonstandardized cephalographs, systemic syndromes, dental anomalies, previous orthodontic treatments or maxillofacial surgeries.

\subsection{Instruments and Variables}

Cephalometric measurements were performed by a single-blind orthodontist using Delta-Dent ${ }^{\circledR}$ software (version 2.0, Outside Format, Cremona, Italy, 2020).

Panoramic radiographs were used to collect information about possible anatomical abnormalities: 
- $\quad$ Alpha angle [12]: angle between the midline and the long axis of MCI. Grade 1: 0-15 — grade 2: 15-30-grade $3:>30^{\circ}$.

- Vertical height of the canine crown [12]: Grade 1: the crown of MCI is located coronal to the cementoenamel junction (CEJ) of the incisor. Grade 2: the crown is located apical to the CEJ but coronal to the middle root area of the incisor. Grade 3: the crown is located apical to the middle root area of the incisor but not beyond its root apex. Grade 4: the crown is located apical to the root apex of the lateral incisor.

- Overlap sector [13]: Sector 1: MC is located medially to the central incisor axis. Sector 2: MC is located between the central and lateral incisor axes. Sector 3: MC is located distally to the axis of the lateral incisor, between the axes of the lateral incisor and the first premolar.

In the test group, panoramic radiographs were also used to measure the ratio between the available space in the alveolar arch and the maximum width of MC.

Lateral cephalometric radiographs were used to measure skeletal relationship angle (ANB) and evaluate PP (Figure 1), sella bridging (Figure 2) and atlas posterior arch deficiency (Figure 3).

The extent of PP osseous anomaly of the atlas vertebra was estimated following the classifications of Cederberg and Stubbs [14,15]: Grade 1-the absence of calcification, Grade 2-the presence of calcifications which extend for less than half the distance between the posterior segment of the upper articular process and the lateral and posterior segment of the superior portion of the posterior atlas arch, Grade 3-calcifications which extend for more than half the distance between the posterior portion of the superior articular process and the posterolateral portion of the upper margin of the posterior arch of the atlas but which do not form a complete ring, Grade 4-calcifications forming a complete bone ring.

The evaluation of the sagittal length of the radiographic image of the atlas posterior arch was also made, so as to define its level of formation: fully formed or deficient.

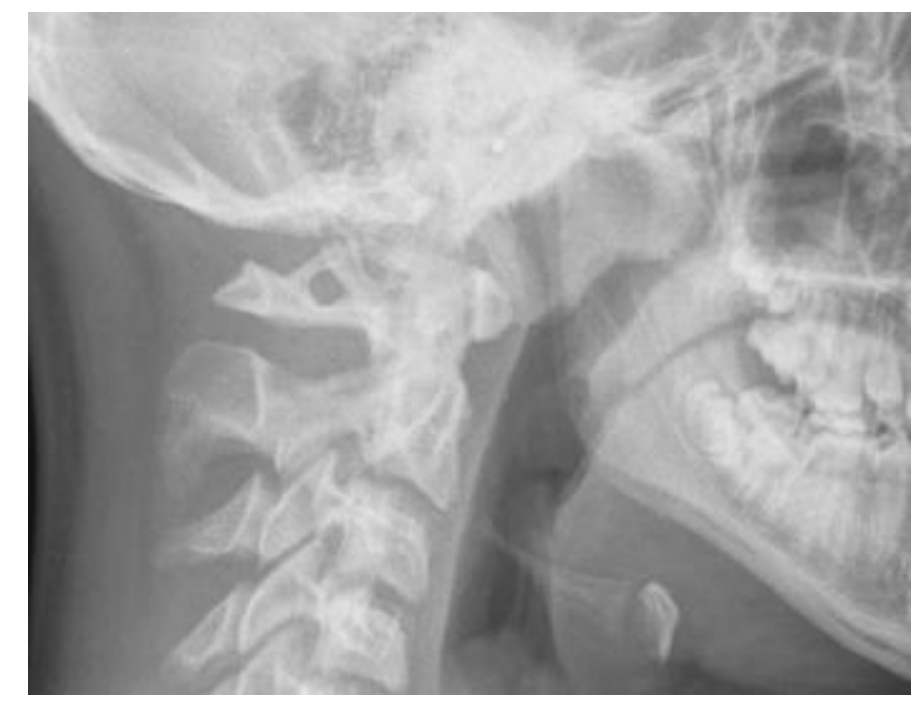

Figure 1. Ponticulus posticus (PP) full ring. 


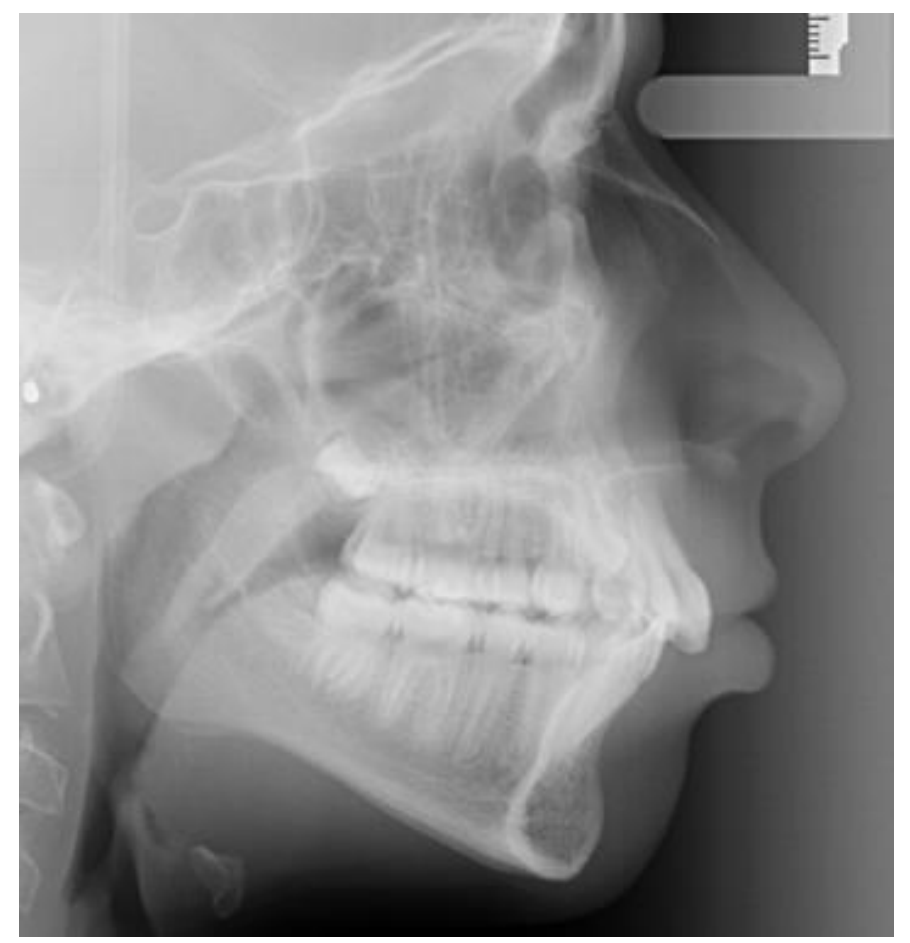

Figure 2. Full sella bridging.

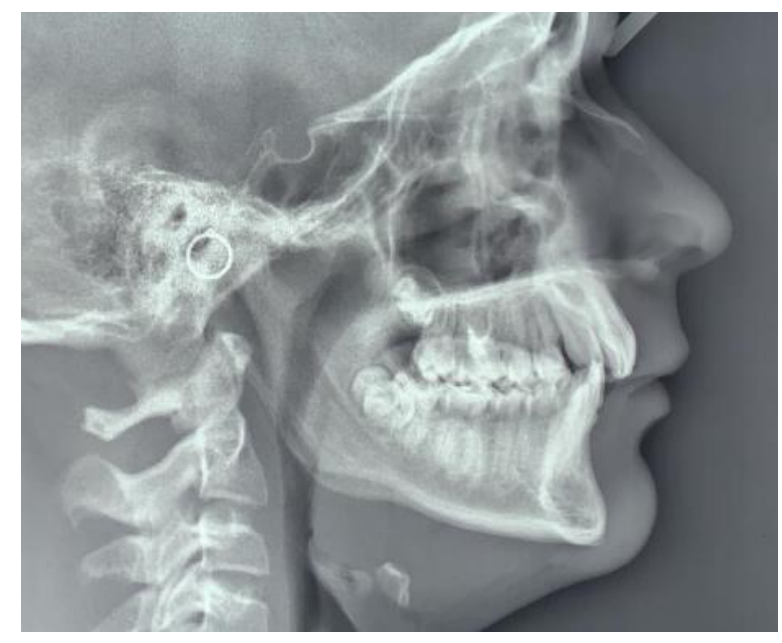

Figure 3. Deficient posterior atlas arch.

Sella turcica bridging measurement was performed measuring interclinoidal distance (from the upper portion of sella tuberculum to the sella turcica dorsum) and the greatest distance/diameter between the tip of sella turcica tuberculum and the posterior sellae contour.

The standard scoring scale by Leonardi et al. [7] was used: the absence of bone calcification and sella bridging (type I), partial calcification (type II), complete calcification (type III).

The sella turcica and pterygopalatine fissure morphologies were analysed by evaluating the measurements according to the criteria by Axelsson et al. [16]: the width/length was considered as the measurement from the tip of the dorsum and the tuberculum while the height/depth of sella and pterygopalatine fissure was a perpendicular line to $\mathrm{w}$-line to the deepest point on the floor of the sella or pterygopalatine fissure. The ratio between $\mathrm{h}$-line and $\mathrm{w}$-line of both anatomical parts was measured (Figure 4). 


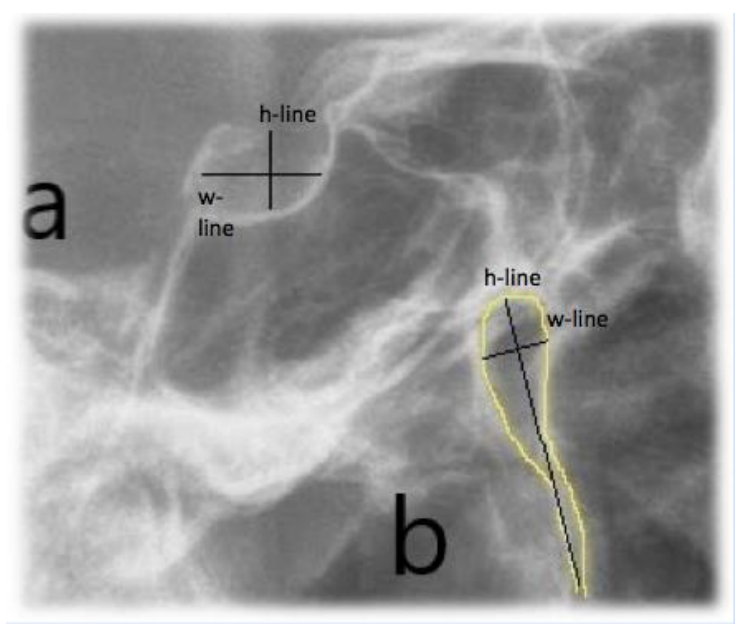

Figure 4. Sella Turcica (a) and pterygopalatine fissure morphology analysis (b). Reference lines: h-line (height/depth) and w-line (width/length).

\subsection{Ethical Approval}

All subjects gave their informed consent for inclusion before they participated in the study. The study was conducted in accordance with the Declaration of Helsinki, and the protocol was approved by the Ethics Committee of University of L'Aquila (L'Aquila, Italy) (Project identification code: 12/2020, date of approval: 11 May 2020).

\subsection{Statistical Analysis}

All parameters were measured twice by the same operator, 15 days after the first measurement, in order to calculate intra-observer reliability by using Cohen's Kappa coefficient (K). K coefficients obtained were as follows: 0.9 for SNA (anterioposterior position of the maxilla), 0.92 for SNB (anterioposterior position of the mandible), 0.89 for PP, 0.93 for SB, 0.95 for APAD, 0.9 for sella shape and 0.91 for pterygopalatine fissure.

Furthermore, inter-observer reliability was evaluated for each patient by using $\mathrm{K}$ coefficient and the values recorded were as follows: 0.88 for SNA, 0.9 for SNB, 0.88 for PP, 0.9 for SB, 0.91 for APAD, 0.88 for sella shape and 0.89 for pterygopalatine fissure.

A blinded statistical analysis was performed.

The intergroup comparison was made with Fisher's exact test and Pearson's chi-square test for APAD, for PP and SB prevalence and grades (\%) and for prevalence in males and in females while Wilcoxon rank-sum (Mann-Whitney) test was adopted for shapes of sella turcica and pterygopalatine fissure. Univariate logistic regression models were used to verify the potential association between all measured parameters and the presence of MCI. Significant parameters were then included in multivariate logistic regression analysis to identify factors independently associated with MCI. Multinomial logistic regression was performed to determine the association between severe MCI (defined as a grade 3 for grade of inclusion, grade 3 or 4 for vertical height and grade 3 for overlap sector) and PP, Sella, Atlas and presented relative risk ratios (RRRs) with $95 \%$ confidence intervals (95\% CIs). All data were analysed with Stata software (version 12; StataCorp, College Station, TX, USA) and the level of significance was set at $p<0.05$.

\section{Results}

Demographic information of the test group and of control group matched for age, sex and skeletal class are reported in Table 1. In the test group, $19.4 \%$ of patients had at least one dental agenesis and $9 \%$ of patients had at least one tooth included in addition to the canine. 
Table 1. Demographic information of the two groups.

\begin{tabular}{ccc}
\hline & Test Group & Control Group \\
\hline NUMBER OF PATIENTS & 67 & 67 \\
\hline MALES & 25 & 25 \\
\hline FEMALES & 42 & 42 \\
\hline AGE (YEARS) & $14.5 \pm 4.8$ & $14.5 \pm 4.8$ \\
\hline SKELETAL CLASS I (\%) and number $(\mathrm{n})$ & $58 \%(\mathrm{n}: 39)$ & $58 \%(\mathrm{n}: 39)$ \\
\hline SKELETAL CLASS II $(\%)$ and number $(\mathrm{n})$ & $30(\mathrm{n}: 20)$ & $30(\mathrm{n}: 20)$ \\
\hline SKELETAL CLASS III $(\%)$ and number $(\mathrm{n})$ & $12(\mathrm{n}: 8)$ & $12(\mathrm{n}: 8)$ \\
\hline
\end{tabular}

The results of the analysis of the anatomical abnormalities in the test group are shown in Table 2.

Table 2. Descriptive results of the test group.

\begin{tabular}{|c|c|c|}
\hline Parameter & Grade & $\begin{array}{l}\text { Percentage } \% \text { and Number } \\
\text { (n) }\end{array}$ \\
\hline \multirow{3}{*}{$\begin{array}{l}\text { Grade of inclusion } \\
\text { (Stivaros-Mandall) }\end{array}$} & G1 & $13.4 \%(9)$ \\
\hline & G2 & $26.8 \%(18)$ \\
\hline & G3 & $59.8 \%(40)$ \\
\hline \multirow{4}{*}{$\begin{array}{l}\text { Vertical height of the canine } \\
\text { (Stivaros-Mandall) }\end{array}$} & 1 & $1.5 \%(1)$ \\
\hline & 2 & $41.8 \%(28)$ \\
\hline & 3 & $50.7 \%(34)$ \\
\hline & 4 & $6 \%(4)$ \\
\hline \multirow{3}{*}{ Overlap sector (Baccetti) } & 1 & $7.5 \%(5)$ \\
\hline & 2 & $44.8 \%(30)$ \\
\hline & 3 & $47.7 \%(32)$ \\
\hline
\end{tabular}

In the test group, $\mathrm{MCI}$ was moderate or severe as regards the angle between the canine axis and interincisive midline and more than half of the inclusions were located particularly apical inside the maxillary bone. Evaluation of the index about the overlap sector showed that inclusions were severe only in a small percentage of cases.

The mean percentage derived from the ratio between the space available in the arch for the eruption of the canine and its maximum width was about $71 \%$.

Table 3 shows the values recorded in the two groups for the following skeletal parameters: PP, $\mathrm{SB}$ and APAD.

The statistical analysis showed a significant difference (chi-square test, $p<0.05$ ) between the two groups for PP: in the test group, a higher mean value of PP was observed with greater severity grade than in the control group: grade 1 was significantly lower in the test group comparing with the control group while grades 2 and 3 were significantly higher in the test group comparing with the control one (chi-square test, $p<0.05$ ). A slightly higher prevalence of grade 4 was also observed in comparison to the controls, however, the difference between the groups was not statistically significant $(p>0.05)$. The multivariate analysis showed a significant difference between the two groups, only for grades 2 and 3. 
Table 3. Descriptive statistics and results of Univariate and Multivariate logistic models for the following skeletal parameters: PP, sella turcica bridging (SB) and atlas posterior arch deficiency (APAD).

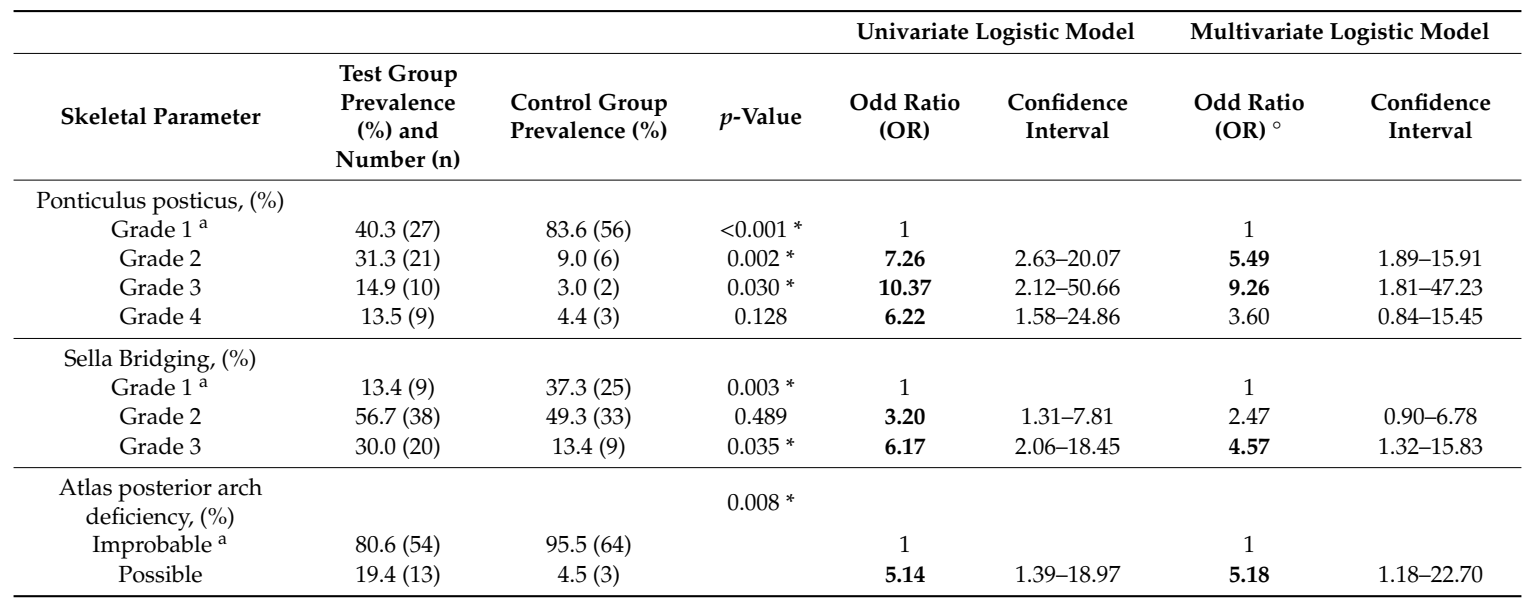

${ }^{*} p<0.05$; Significant ORs are shown in bold; ${ }^{\text {a }}$ reference category; ${ }^{\circ}$ : OR adjusted for the other factors in the model.

The test group exhibited a higher percentage of sella bridging compared with the control group (chi-square test, $p<0.05$ ). Furthermore, grade 1 was significantly lower in the test group compared with the control group while grade 3 was detected in higher prevalence in the test group compared with the control one (chi-square test, $p$ : 0.02 , OR (odd radio): 0.36, CI: 0.15-0.88). No significant differences $(p>0.05)$ were recorded for grade 2 . The multivariate analysis exhibited a significant ORs for grade 3.

A higher percentage of APAD was found in the test group and the difference between test and control group was statistically significant both with univariate analysis (chi-square test, $p<0.05$ ) and multivariate analysis. A significant difference (Wilcoxon rank-sum (Mann-Whitney) test, $p<0.05$ ) between the two groups was also recorded for the shape of pterygopalatine fissure (the fissure in patients with MCI was elongated than in patients who do not have dental abnormalities) while the difference for the shape of sella turcica was not significant (Wilcoxon rank-sum (Mann-Whitney) test, $p>0.05$ ) (Table 4).

Table 4. Descriptive statistics and results for the shape of sella turcica and of pterygopalatine fissure in the two groups.

\begin{tabular}{cccc}
\hline Skeletal Parameter & Test Group (Mean \pm SD) & Control Group (Mean \pm SD) & $p$-Value \\
\hline $\begin{array}{c}\text { Shape of sella turcica } \\
\text { (height/diameter) }\end{array}$ & $0.88 \pm 0.66$ & $0.83 \pm 0.15$ & 0.64 \\
\hline $\begin{array}{c}\text { Shape of pterygopalatine fissure } \\
\text { (lenght/width) }\end{array}$ & $4.50 \pm 1.05$ & $3.96 \pm 0.69$ & $0.004 *$ \\
\hline & ${ }^{*} p<0.05$. SD: standard deviation.
\end{tabular}

We did not observed any significant difference (chi-square test, $p>0.05$ ) between males and females as regards PP, SB and APAD (Table 5). 
Table 5. Prevalence of skeletal measurements in males and in females.

\begin{tabular}{cccc}
\hline Skeletal Parameter & Male (\%) & Female (\%) & $p$-Value \\
\hline Ponticulus posticus, (\%) & & & \\
Grade 1 a $^{\text {Grade 2 }}$ & 54.0 & 66.7 & 0.198 \\
Grade 3 & 28.0 & 15.5 & 0.118 \\
Grade 4 & 12.0 & 7.1 & 0.363 \\
Sella Bridging, (\%) & 6.0 & 10.7 & 0.534 \\
Grade 1 & & \\
Grade 2 & 26.0 & 25.0 & 0.999 \\
Grade 3 & 54.0 & 52.4 & 0.999 \\
\hline Atlas posterior arch deficiency, (\%) & 20.0 & 22.6 & 0.830 \\
Improbable ${ }^{\text {a }}$ & 86.0 & & 0.571 \\
Possible & 14.0 & 10.7 & \\
\hline $\begin{array}{c}\text { Shape of pterygopalatine fissure } \\
\text { (lenght/width), (mean } \pm \text { SD) }\end{array}$ & $4.16 \pm 0.82$ & $4.28 \pm 0.99$ & 0.804 \\
\hline
\end{tabular}

${ }^{*} p<0.05 ;{ }^{a}$ : reference category.

The univariate logistic analysis for severe MCI exhibited a significant difference (Chi-square test, $p<0.05$ ) only for one parameter (SB grade 3). However, with multivariate logistic analysis, we did not record any significant difference (Table 6). Furthermore, relative risk ratios of having severe or not severe MCI by multinomial logistic regression were calculated and a significant association $(p<0.05)$ was found for PP (grade 2 and 3 ) and for APAD, while for SB, we did not observe any significant difference $(p>0.05)$ (Table 7).

Table 6. Descriptive statistics and results of univariate and multivariate logistic analysis with not severe/severe maxillary canine impaction (MCI) for the following skeletal parameters: PP, SB and APAD.

\begin{tabular}{|c|c|c|c|c|c|c|c|}
\hline \multirow[b]{2}{*}{ Skeletal Parameter } & \multirow[b]{2}{*}{$\begin{array}{c}\text { Not Severe } \\
\text { Prevalence (\%) }\end{array}$} & \multirow[b]{2}{*}{$\begin{array}{c}\text { Severe } \\
\text { Prevalence (\%) }\end{array}$} & \multirow[b]{2}{*}{$p$-Value } & \multicolumn{2}{|c|}{ Univariate Logistic Model } & \multicolumn{2}{|c|}{ Multivariate Logistic Model } \\
\hline & & & & $\begin{array}{l}\text { Odd Ratio } \\
\text { (OR) }\end{array}$ & $\begin{array}{l}\text { Confidence } \\
\text { Interval }\end{array}$ & $\begin{array}{l}\text { Odd Ratio } \\
\text { (OR) }{ }^{\circ}\end{array}$ & $\begin{array}{l}\text { Confidence } \\
\text { Interval }\end{array}$ \\
\hline \multicolumn{8}{|l|}{$\begin{array}{l}\text { Ponticulus posticus, } \\
\qquad(\%)\end{array}$} \\
\hline Grade $1^{\mathrm{a}}$ & 38.5 & 42.9 & 0.803 & 1 & & 1 & \\
\hline Grade 2 & 35.9 & 25.0 & 0.428 & 0.62 & $1.92-2.04$ & 0.62 & $0.17-2.20$ \\
\hline Grade 3 & 12.8 & 17.9 & 0.731 & 1.25 & $0.29-5.34$ & 1.37 & $0.31-6.19$ \\
\hline Grade 4 & 12.8 & 14.3 & 1 & 1 & $0.22-4.56$ & 0.85 & $0.16-4.50$ \\
\hline \multicolumn{8}{|l|}{ Sella Bridging, $(\%)$} \\
\hline Grade $1^{\text {a }}$ & 10.3 & 17.9 & 0.474 & 1 & & 1 & \\
\hline Grade 2 & 51.3 & 64.3 & 0.326 & 0.72 & $0.16-3.10$ & 0.77 & $0.17-3.55$ \\
\hline Grade 3 & 38.5 & 17.9 & $<0.001 *$ & 0.26 & $0.05-1.40$ & 0.29 & $0.05-1.58$ \\
\hline $\begin{array}{l}\text { Atlas posterior arch } \\
\text { deficiency, }(\%)\end{array}$ & & & 0.326 & & & & \\
\hline Improbable ${ }^{a}$ & 84.6 & 75.0 & & 1 & & 1 & \\
\hline Possible & 15.4 & 25.0 & & 1.83 & $0.54-6.02$ & 2.20 & $0.58-8.03$ \\
\hline
\end{tabular}

${ }^{*} p<0.05$; Significant ORs are shown in bold; ${ }^{\text {a }}$ : reference category; ${ }^{\circ}$ : OR adjusted for the other factors in the model. 
Table 7. Estimated relative risk ratios of having severe or not severe MCI by multinomial logistic regression.

\begin{tabular}{|c|c|c|c|c|c|c|}
\hline & \multicolumn{3}{|c|}{ MCI (Not Severe) } & \multicolumn{3}{|c|}{ MCI (Severe) } \\
\hline & RRR & IC $95 \%$ & $p$-Value & RRR & IC $95 \%$ & $p$-Value \\
\hline \multicolumn{7}{|c|}{ Ponticulus posticus, (\%) } \\
\hline Grade $1^{\mathrm{a}}$ & 1 & & & 1 & & \\
\hline Grade 2 & 1.86 & $0.70-3.03$ & 0.002 & 1.45 & $0.14-2.77$ & 0.030 \\
\hline Grade 3 & 2.05 & $0.26-3.84$ & 0.024 & 2.41 & $0.62-4.20$ & 0.008 \\
\hline Grade 4 & 1.26 & $1.25-4.15$ & 0.124 & 1.48 & $-0.43-3.06$ & 0.140 \\
\hline \multicolumn{7}{|c|}{ Sella Bridging, (\%) } \\
\hline Grade $1^{\mathrm{a}}$ & 1 & & & 1 & & \\
\hline Grade 2 & 1.06 & $-0.22-2.34$ & 0.105 & 0.74 & $-0.50-1.99$ & 0.241 \\
\hline Grade 3 & 2.00 & $0.54-3.45$ & 0.007 & 0.71 & $-0.90-2.34$ & 0.384 \\
\hline \multicolumn{7}{|c|}{$\begin{array}{c}\text { Atlas posterior arch } \\
\text { deficiency, }(\%)\end{array}$} \\
\hline Improbable ${ }^{a}$ & 1 & & & 1 & & \\
\hline Possible & 1.25 & $-0.39-2.91$ & 0.014 & 1.96 & $0.40-3.53$ & 0.014 \\
\hline
\end{tabular}

\section{Discussion}

Our findings showed that PP, SB and APAD were significantly correlated with the occurrence of $\mathrm{MCI}$ and this is in agreement with other studies [1]. The lateral radiographs only provide a sagittal view while a computed tomography examination may be helpful to confirm this diagnosis; however, Sonnesen et al. [17] demonstrated that the presence of skeletal variations in the cervical vertebral anatomy exhibited a high concordance between lateral radiographs and CBCT (cone beam computed tomography) radiographs, therefore the lateral radiographs are often sufficient to identify skeletal abnormalities in the cervical vertebral section. Moreover, it is important to highlight that each subject was not treated orthodontically before the radiographs were taken; in fact, orthodontic patients may exhibit some anatomical variants but not MCI because of the improvement due to the orthodontic treatment. Furthermore, patients of the control group had some orthodontic problems; however, a normal control group without any orthodontic problem was not included since, in a retrospective study, only the patients with orthodontic problems were allowed to perform lateral cephalograms.

Since these skeletal anomalies seem to be detectable radiographically at an early age, this could help the clinician to suspect a possible dental displacement.

Tripodi et al. stated that the presence of PP was independent of age, therefore PP cannot be considered exclusively as a process of calcification or ossification due to aging but it is congenital in origin [18].

Ortiz et al. [19] found a non-statistically significant association between increased sella bridging and palatally displaced canine while Leonardi et al. [7] observed an increased SB in subjects with MCI. It was observed that the sellae length was almost immutable, whereas the depth and diameter changed with growth, thus the morphological aberration about its length occurs during pre-natal growth while post-natal modification is responsible just for the variations in size [20].

Sella turcica shape does not depend on patients' age in the age range of 6 through 21 and there could be an $\mathrm{x}$-linked genetic disorder behind SB as it has been shown for the MCI However, most cases of SB are detected at early stages in life calcification may continue over time [16].

The atlas develops during the seventh week of gestation, the fusion of the posterior arch synchondrosis usually occurs at age 5 years and the ossification is complete at 7 years of age [2]. Morphological defects of atlas (C1) are therefore congenital and they can be found in patients' radiographs at an age that is considered the minimum age for collaboration and the minimum age for requiring radiological investigations. 
PP, SB and APAD can be related to medically relevant signs and symptoms: patients with APAD may show head and neck pain [3].

Several endocrinological and neurological disorders are associated with SB; higher prevalences of sella bridges have been recorded in subjects with severe craniofacial deformities and with dental transpositions [21]. Becktor et al. found a significant association between SB and severe cranial malformations, the patients of which required surgical therapy rather than the subjects treated only with orthodontic treatments [22]. Compression of the nervous and vascular structures passing through arcuate foramen may result in a combination of symptoms forming a picture of vertebrobasilar insufficiency. This consists of cervical migraine, neurosensory-type hearing loss, neck pain, vertigo, shoulder/arm pain, and in some instances, even loss of postural muscle tone and consciousness and surgical excision of such an arcuate foramen appears to alleviate these symptoms [2].

Therefore, a syndromic picture characterized by skeletal anomalies and MCI could be supported by genetic theory.

Moreover, in this study, we found a decreased width of the pterygopalatine fissure. Nevertheless, in previous studies, it was observed that in patients with an abnormal direction of maxillary canines eruption, the vertical height and sagittal length of the maxilla were reduced [23]. A decreased sagittal width of the pterygopalatine fissure may be caused by a deviated maxillary growth which in turn is linked to a deviated skeletal cranial growth while, on average, the space available for the eruption of the maxillary canines seemed sufficient to suggest a non-existent cause of mechanical obstacle to the physiological eruption. The relationship between skeletal anomalies and MCI may be linked to the activation of neural crest cells and homeobox genes during growth [1]. Neural crest cells undergo a transition from ectoderm to mesenchyme due to some biological signals such as bone morphogenetic protein BMP2 and BMP4, as they migrate to the pharyngeal arches to form the bones of the face, and are necessary for the formation of odontoblasts, dental pulp and periodontium; furthermore, paired box genes PAX9 mutations have been reported to be associated with dental agenesis [7]. Indeed, their expression is important to direct the tooth eruption but also to mediate the interaction between notochord and sclerotomes [8], from which the vertebrae are formed, and this could explain the association with the deficit of the posterior arch of $\mathrm{C} 1$.

Axelsson [16] also found that sella turcica bridging was more common in females, while we did not find any differences according to sex. Regarding the association of specific variants with different degrees of $\mathrm{MCI}$, univariate and multivariate logistic analysis did not show any significant results, while multinomial logistic regression exhibited that PP and APAD were significantly increased in patients with severe $\mathrm{MCI}$ in comparison to subjects without severe MCI. Therefore, a slight association of the specific variants (PP and APAD) with higher degrees of MCI may be suspected and further studies will be necessary in order to confirm the results of the present study.

\section{Conclusions}

The occurrence of SB, PP and APAD were positively associated with MCI and the null hypothesis of the study was rejected. Furthermore, an association between MCI and an elongated pterygopalatine fissure was demonstrated.

Since these skeletal anomalies are detectable in cephalometric radiographs at an early age, they can be considered by orthodontists for a precocious diagnosis of MCI. It is also important that the orthodontist reports the presence of these skeletal variants in the medical record as they may be related to some medically relevant symptoms.

Author Contributions: Conceptualization, M.P. and M.R.G.; methodology, S.L.; software, F.F.; validation, V.Q. and G.M.; formal analysis, F.F.; investigation, S.L.; resources, S.M.; data curation, M.P.; writing-original draft preparation, M.P.; writing-review and editing, M.R.G.; visualization, G.M.; supervision, V.Q.; project administration, M.R.G. All authors have read and agreed to the published version of the manuscript.

Funding: This research received no external funding.

Conflicts of Interest: The authors declare no conflict of interest. 


\section{References}

1. Leonardi, R.; Barbato, E.; Vichi, M.; Caltabiano, M. Skeletal anomalies and normal variants in patients with palatally displaced canines. Angle Orthod. 2009, 79, 727-732. [CrossRef] [PubMed]

2. Kim, M.S. Anatomical variant of Atlas: Arcuate foramen, occpitalization of Atlas, and defect of posterior arch of Atlas. J. Korean Neurosurg. Soc. 2015, 58, 528-533. [CrossRef]

3. Sagiuchi, T.; Tachibana, S.; Sato, K.; Shimizu, S.; Kobayashi, I.; Oka, H.; Fujii, K.; Kan, S. Lhermitte sign during yawning associated with congenital partial aplasia of the posterior arch of the atlas. Am. J. Neuroradiol. 2006, 27, 258-260. [PubMed]

4. Alkofide, E.A. The shape and size of the sella turcica in skeletal Class I, Class II, and Class III Saudi subjects. Eur. J. Orthod. 2007, 29, 457-463. [CrossRef] [PubMed]

5. Haji Ghadimi, M.; Amini, F.; Hamedi, S.; Rakhshan, V. Associations among sella turcica bridging, atlas arcuate foramen (ponticulus posticus) development, atlas posterior arch deficiency, and the occurrence of palatally displaced canine impaction. Am. J. Orthod. Dentofac. Orthop. 2017, 151, 513-520. [CrossRef]

6. Scribante, A.; Sfondrini, M.F.; Cassani, M.; Fraticelli, D.; Beccari, S.; Gandini, P. Sella turcica bridging and dental anomalies: Is there an association? Int. J. Paediatr. Dent. 2017, 27, 568-573. [CrossRef]

7. Leonardi, R.; Barbato, E.; Vichi, M.; Caltabiano, M. A sella turcica bridge in subjects with dental anomalies. Eur. J. Orthod. 2006, 28, 580-585. [CrossRef]

8. Kjaer, I.; Becktor, K.B.; Lisson, J.; Gormsen, C.; Russell, B.G. Face, palate, and craniofacial morphology in patients with a solitary median maxillary central incisor. Eur. J. Orthod. 2001, 23, 63-73. [CrossRef]

9. Kendrick, G.S.; Biggs, N.L. Incidence of the ponticulus posticus of the first cervical vertebra between ages six to seventeen. Anat. Rec. 1963, 145, 449-453. [CrossRef]

10. Miletich, I.; Sharpe, P.T. Neural crest contribution to mammalian tooth formation. Birth Defects Res. Part C Embryo Today Rev. 2004, 72, 200-212. [CrossRef]

11. Matsuoka, T.; Ahlberg, P.E.; Kessaris, N.; Iannarelli, P.; Dennehy, U.; Richardson, W.D.; McMahon, A.P.; Koentges, G. Neural crest origins of the neck and shoulder. Nature 2005, 436, 347-355. [CrossRef] [PubMed]

12. Stivaros, N.; Mandall, N.A. Radiographic factors affecting the management of impacted upper permanent canines. J. Orthod. 2000, 27, 169-173. [CrossRef] [PubMed]

13. Baccetti, T.; Crescini, A.; Nieri, M.; Rotundo, R.; Pini Prato, G.P. Orthodontic treatment of impacted maxillary canines: An appraisal of prognostic factors. Prog. Orthod. 2007, 8, 6-15.

14. Stubbs, D.M. The arcuate foramen. Variability in distribution related to race and sex. Spine 1992, 17, $1502-1504$. [CrossRef]

15. Cederberg, R.A.; Benson, B.W.; Nunh, M. DEJ Arcuate foramen: Prevalence by age, gender and degree of calcification. Clin. Orthod. Res. 2000, 3, 62-67. [CrossRef]

16. Axelsson, S.; Storhaug, K.; Kjaer, I. Post-natal size and morphology of the sella turcica. Longitudinal cephalometric standards for Norwegians between 6 and 21 years of age. Eur. J. Orthod. 2004, 26, 597-604. [CrossRef]

17. Sonnesen, L.; Jensen, K.E.; Petersson, A.R.; Petri, N.; Berg, S.; Svanholt, P. Cervical vertebral column morphology in patients with obstructive sleep apnoea assessed using lateral cephalograms and cone beam CT. A comparative study. Dento Maxillofac. Radiol. 2013, 42, 20130060. [CrossRef]

18. Tripodi, D.; Tieri, M.; Demartis, P.; Pero, G.; Marzo, G.; D’Ercole, S. Ponticulus posticus: Clinical and CBCT analysis in a young Italian population. Eur. J. Paediatr. Dent. 2019, 20, $219-223$.

19. Ortiz, P.M.; Tabbaa, S.; Flores-Mir, C.; Al-Jewair, T. A CBCT investigation of the association between sella-turcica bridging and maxillary palatal canine impaction. Biomed. Res. Int. 2018, 2018, 4329050. [CrossRef]

20. Power, S.M.; Short, M.B. An investigation into the response of palatally displaced canines to the removal of deciduous canines and an assessment of factors contributing to favourable eruption. Br. J. Orthod. 1993, 20, 215-223. [CrossRef]

21. Leonardi, R.; Farella, M.; Cobourne, M.T. An association between sella turcica bridging and dental transposition. Eur. J. Orthod. 2011, 33, 461-465. [CrossRef] [PubMed] 
22. Becktor, J.P.; Einersen, S.; Kjaer, I. A sella turcica bridge in subjects with severe craniofacial deviations. Eur. J. Orthod. 2000, 22, 69-74. [CrossRef] [PubMed]

23. Larsen, H.J.; Sorensen, H.B.; Artmann, L.; Christensen, I.J.; Kjaer, I. Sagittal, vertical and transversal dimensions of the maxillary complex in patients with ectopic maxillary canines. Orthod. Craniofac. Res. 2010, 13, 34-39. [CrossRef] [PubMed] 